\title{
TADARRUJ DALAM BERDAKWAH
}

\author{
Jeje Zaenudin \\ jeje@stidnatsir.ac.id \\ Program Studi Komunikasi Penyiaran Islam \\ Sekolah Tinggi Ilmu Da’wah Mohammad Natsir, Indonesia
}

\begin{abstract}
ABSTRAK
Tujuan Penelitian: Untuk mengetahui tadarruj dalam berdakwah. Metode Penelitian: Kualitatif. Hasil Penelitian: Penjelasan dari aspek kebahasaan, maupun proses penurunan ayat Al-Qur'an dan hadits Nabi sebagaimana telah dikemukakan, dapat memberi pengertian bahwa arah tadarrij secara umum adalah dari yang mudah kepada yang susah atau dari yang ringan kepada yang berat; dari yang global kepada yang rinci; dari yang sederhana kepada yang kompleks dan sempurna. Kewajiban-kewajiban ritual, seperti shalat, puasa, dan zakat berkembang dari makna serta praktek yang sederhana ke makna dan praktek yang detil dan kompleks. Demikian juga kewajiban membela agama yang semula bersifat defensif dan menghindari konfrontasi senjata, berkembang menjadi kebolehan membela diri dengan senjata hingga diwajibkannya berjihad dengan perang.
\end{abstract}

Kata Kunci: da'wah, tadarruj.

\section{PENDAHULUAN}

\section{Makna Tadarruj}

Penelusuran mengenai asal-usul kata تدرّج (tadarruj) menunjukan bahwa kata tersebut berasal dari tiga suku kata درج جرج, yang dibaca dengan dua bentuk: da-ra-ja dan da-ri-ja. Menurut Az Zubaidi, pengarang kitab kamus Tâj al 'Arusy min Jawâhir al Qâmus, apabila dibaca dengan fathah (dara-ja), maka artinya berjalan dengan perlahan-lahan seraya merayap atau merangkak karena lemahnya, seperti kalimat "daraja al shabiyu wa al syaikhu” yang berarti “orang tua dan bayi itu berjalan dengan lemah dan merayap". 'Tetapi ketika dibaca dengan kasrab (da-ri-ja), maka artinya

${ }^{1}$ Muhammad bin Muhammad bin Abdul Razaq Al Husaini Abul Faidh Az Zubaidi, Taj al 'Urusy min Jawâhir al Qâmus (Beirut: Dar el Fikr, tt.), Juz V, hlm. 553

1 I Jurnal Dakwah | Vol.1 No.1 |2018 
adalah "berjalan tetap pada jalan yang jelas" (lazima al mubajjab); juga berarti "naik pada tangga-tangga" (sha'ida al marâtib). ${ }^{2}$

Dari asal kata tersebut lahir berbagai pecahan kata yang banyak dengan arti yang berlainan. Di antaranya muncul kata الدَّرَجَة yang berarti posisi dan kedudukan. ${ }^{3}$ Demikian juga kata اسنْتِدرَاج mengelabui dan mendekatinya. Sehingga ada ungkap an "Allah mengistidrâj hamba-Nya", maknanya, "setiap hamba itu menambah perbuatan dosanya Allah menambah ni'mat kepadanya sehingga menyebabkan orang tersebut jadi lalai dari mohon ampunan". Maka dengan demikian ia sedang berjalan secara perlahan tapi pasti menuju kebinasaannya, yaitu kematian yang menyengsarakannya. Karena itu pula kata "da-ra-ja" digunakan dalam arti kematian, sebab orang yang mati merapat ke bumi tidak lagi dapat berjalan atau naik ke atas. karena itu Abu Harits $\mathrm{Al}$ Anshari menyimpulkan bahwa antonim dari kata al tadarrij adalah al tadarruk. Tadarruj adalah bergerakan perlahan yang bersifat meningkat menuju kebaikan dan kesempurnaan; sedang tadarruk adalah pergerakan secara perlahan yang bersifat menurun menuju keburukan. ${ }^{4}$

Dengan pendekatan kebahasaan sebagaimana dikemukakan para ahli di atas, terlihat bahwa kata tadarrij tidak terlepas dari dua makna pokok: adanya gerakan, seperti berjalan; dan adanya keberangsuran atau tahapan yang bersifat meningkat. Sedang kalau pergerakannya itu ke arah menurun atau ke belakang maka disebut istidrâj atau tadarruk

Roohi Baabaki dalam Kamus Arab-English Dictionary, mengartikan tadarruj ke dalam bahasa Inggris sebagai "gradual edvance (ment) or progress (by steps); successive steps...”(perkembangan atau kemajuan secara bertahap). ${ }^{5}$ Gradual dalam bahasa Inggris berarti juga "proceeding by degrees; slow but steady in progress, as gradual improvement". ${ }^{6}$ Atas dasar itu penulis menggunakan kata "gradualitas" sebagai padanan kata al tadarruj.

Sementara itu, gradual itu sendiri dalam Kamus Besar Bahasa Indonesia diartikan "berangnsur-angsur atau sedikit demi sedikit". Sama

\section{${ }^{2}$ Ibid, hlm. 554}

${ }^{3}$ Muhammad bin Ya'kub al Fairuz Abadi, Al Qâmûs al Muhîth (Beirut: Dar el Fikr, tt.), hlm. 241

${ }^{4} \mathrm{Abu}$ Harits Al Anshari, Iglâq al Mudraj 'al Faqîh al Tadarruj, (Yordan: Muassasah Nur I'lamiyah. t.t), hlm. 55

${ }^{5}$ Roohi Baabaki, Al Mawrid: A modern Arabic-english Dictionary, (Beirut: Darul ilm lil malayin. 1997), hlm. 300

${ }^{6}$ Lewis M.Adams dkk(ed.) Webster's new American Dictionary, (New York: Books, INC. 1960) hlm. 403 
persis dengan makna tadarruj dalam bahasa Arab, yaitu “taqaddama sya'an fa syaian". 7

\section{Tadarruj sebagai Sunnatullah}

Dengan sifat Kemahakuasaannya yang mutlak, mudah bagi Allah menciptakan apapun secara sekaligus dan tiba-tiba. Tetapi cara itu tidaklah ditempuh oleh Allah Ta'ala. Dia menjadikan segala sesuatu dengan kehendak-Nya melalui cara bertahap dan berangsur-angsur, atau tadarrij. Alam semesta diciptakannya pada enam masa; tumbuhan, binatang, dan manusia diciptakan-Nya secara beringsut dari kecil menjadi besar, dewasa, kokoh, kuat, tua, melemah, dan mati; ditetapakan-Nya perputaran planet-planet, dipergilirkannya siang dan malam sehingga menimbulkan waktu yang bertahap, dari detik ke menit, jam, hari, pekan, bulan, hingga tahun. Alam semestapun menjadi mengenal usia.

Sebagaimana ketetapannya dalam penciptaan secara berangsurangsur, maka Allah Ta'ala menurunkan syariat agama-Nya juga secara bertahap. Dari umat-keumat, generasi manusia saling bergantian, para Nabi datang membawa syariat saling melanjutkan, hingga disempurnakan dan ditutup oleh Nabi Muhammad SAW. Beliau menggambarkan bahwa perumpamaan diutusnya para Nabi dengan beliau seperti seseorang yang membangun rumah secara berangsur-angsur hingga kemudian dilengkapi pembangunannya dengan batu bata yang terakhir. ${ }^{8}$ Batu bata terakhir itu tiada lain adalah beliau, Nabi Muhammad SAW yang kepada beliau turun ayat yang menegaskan bahwa misi dakwah dan wahyu telah sempurna. "Pada hari ini Aku telah sempurnakan bagi kamu agama kalian..." (Al Maidah ayat 3)

Meskipun nabi Muhammad adalah penyempurna dan penutup semua rasul, tetapi syariat Islam diturunkan kepada belia secara bertahap pula. Sebagaimana ditunjukan oleh fakta historis dan penegasan ayat-ayat Al Qur'an sendiri.

Pertama, fakta historis pewahyuan Al Qur'an. Sebagai sumber syariat Islam, Al-Qur'an diturunkan kepada Nabi SAW secara berangsur dalam rentang waktu kurang lebih duapuluh dua tahun. Keberangsuran

\footnotetext{
${ }^{7}$ Muhamad Farid Wajdi, Dâirah maarif al qarnil 'isrin (Beirut: Darul Ma'rifah. 1971), hlm. 21

${ }^{8}$ Shahih Muslim pada bab Bayânu mitslihi shallallahu 'alaihi wa sallam mitslu al nabiyîn, hadits no. 6023.
} 
tersebut berlangsung dengan melibatkan kaum muslim generasi awal sebagai pelaku utama hukum-hukumnya.

Kedua, penegasan eksplisit dari beberapa ayat Al-Qur'an itu sendiri bahwa Al-Qur'an memang diturunkan secara bertahap. Al-Qur'an menyatakan,

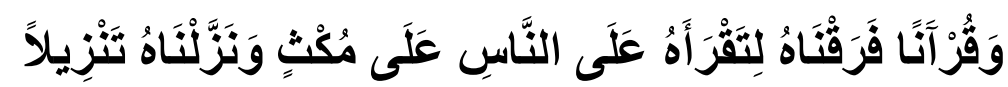

'Dan Al Qur'an itu telah Kami turunkan dengan berangsur-angsur agar kamu membacakannya perlaban-laban kepada manusia dan Kami menurunkannya bagian demi bagian”. (Al Isrâ : 106)

Pada ayat lain bahkan ditegaskan bantahan kepada kaum musyrik yang merasa heran serta mempertanyakan mengapa Al-Qur'an harus turun sedikit demi sedikit, tidak secara sekaligus.

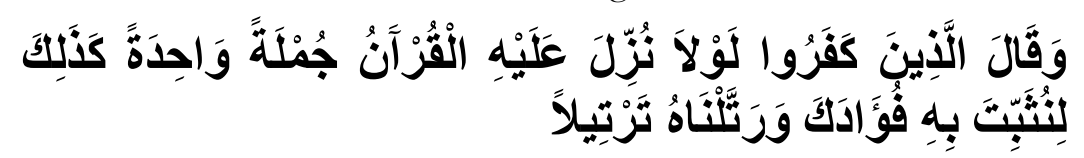

"Berkatalah orang-orang yang kafir: "Mengapa Al Qur'an itu tidak diturunkan kepadanya sekali turun saja?"; demikianlah supaya Kami perkuat hatimu dengannya dan Kami membacakannya secara tartil (teratur dan benar)". 9

\section{HASIL DAN DISKUSI}

\section{Tadarruj dalam Dakwah}

Sebagaimana Al-Qur'an turun secara berangsur-angsur, maka Nabi mendakwahkannya kepada umatpun secara berangsur-angsur. Keberangsuran dakwah beliau sejalan dengan keberangsuran pewahyuan Al-Qur'an. Sejarah mencatat praktek dan pengajaran Nabi SAW kepada para shahabatnya. Nabi telah mengajarkan kepada para sahabatnya agar mendakwahkan Islam secara bertahap. Seperti yang diriwayatkan oleh Al Bukhary (194-256 H), ketika Nabi mengutus Mu'adz bin Jabal ke Yaman beliau memberikan pesan sebagai langkah-langkah kebijakan dalam berdakwah,

${ }^{9}$ Ibid, Surat Al Furqân [25] ayat 32

4 IJurnal Dakwah | Vol.1 No.1 | 2018 


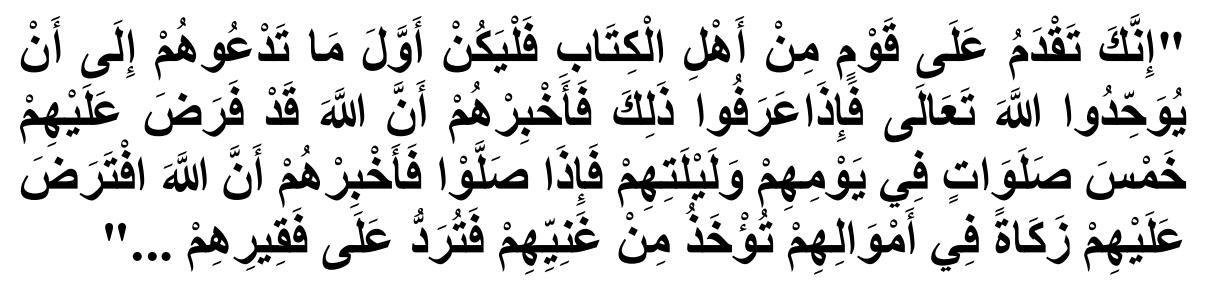

"Sesunggubnya kamu akan mendatangi suatu kaum dari Abli Kitab, maka bendaklah yang pertama kali kamu ajarkan kepada mereka adalah tentang mengesakann Allah. Jika mereka telah mengerti tentang itu maka ajarkanlab kepada mereka shalat lima waktu sehari semalam, jika mereka telah melaksanakan shalat maka ajarkan kepada mereka babwa Allah mewajibkan zakat dari harta mereka yang diambil dari orang-orang kaya mereka dan dikembaliken kepada orang-orang miskin mereka..."10.

Mua'dz diutus Nabi ke Yaman pada tahun ke-9 H sepulangnya Rasulullah dari perang Tabuk. Utusan ke Yaman ini rombongan pertama, bersama Abu Musa Al Asy 'ary ke wilayah Zabid, And dan Sahil; Muadz ke wilayah Jundal; Khalid bin Said ke wilayah San'a; Al Muhajir bin Abi Umayah ke Kindah; dan Ziyad bin Lubaid ke wilayah Hadramaut. Muadz sebagai pemimpin dan qadhinya. ${ }^{11}$ Pada tahun ke sepuluh, Nabi kembali mengirim utusan dakwah yang dipimpin Ali bin Abu Thalib bersama Khalid bin Walid.

Dalam pesan Nabi kepada Muadz dan Abu Musa Al Asy'ari di atas jelas sekali menunjukan perintah menempuh cara gradual dalam pengajaran Islam kepada kaum yang baru memeluk Islam. Meskipun pada pesan Nabi tersebut hanya disebutkan beberapa jenis hukum ibadah yang diajarkan kepada Muadz, tetapi spirit dari pesan tersebut nyatalah perintah bertahap dalam mendakwahkan Islam kepada umat manusia.

Keberangsuran dalam dakwah sebagaimana keberangsuran dalam penurunan syariat Islam telah menjadi kesaksian dan pandangan para shahabat Nabi tentang gradualitas ajaran Islam. Sebagai contoh apa yang diriwayatkan oleh Al Bukhari, bahwa satu ketika ada orang Irak datang kepada Aisyah meminta catatan Al-Qur'an untuk ia menyalinnya. Aisyah mengatakan kepada orang tersebut:

\footnotetext{
${ }^{10} \mathrm{Abu}$ Abdillah Muhammad bin Ismail Al Bukhary, Matnul Bukhâry Masykûl bihâsyiyah al Sindy, (Kairo: Dar el Fikr, tt), Jilid. IV, hal. 273

${ }^{11}$ Badrudin Al Ainy, Umdatul qâry syarah Shahih al Bukhary, (Beirut: Dar el Fikr, tt.) Juz XIII, hlm. 184.
} 


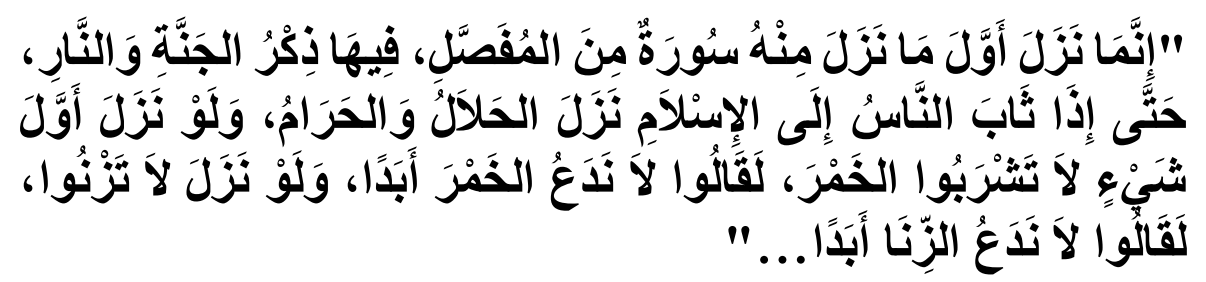

"Sesungguhnya( surat) yang pertama-tama turun adalah surat-surat yang pendek yang di dalamnya menerangkan surga dan neraka. Ketika manusia sudab menerima Islam turunlah tentang halal dan haram. Kalaulah yang pertama turun itu, "Jangan kalian minum khamar!", niscaya mereka mengatakan, "Kami tidak akan sekalikali meninggalkan khamr!'; kalaulah turun, "Jangan kalian berzina!", niscaya mereka akan mengatakan, "Kami tidak akan meninggalkan zina!"....",2

Penjelasan Aisyah menjadi point penting bagi penelusuran konsep tadarruj dalam penurunan wahyu dengan tadarruj sebagai konsep dalam pembentukan dan pelaksanaan syariat (hukum) Islam. Bahwa keberangsuran penurunan wahyu berkorelasi dengan kesiapan dan kemantapan iman kaum muslimin. Kesiapan kaum muslimin dalam menerima hukum yang asing bagi mereka, seperti pengharaman minuman keras, praktek riba, dan perzinaan, terkait dengan kesiapan perubahan pemikiran, budaya, dan perilaku sosial. Lebih jauh, penegakan suatu hukum juga terkait dengan kesiapan perangkat hukumnya, seperti lembaga peradilan dan para hakimnya.

Perubahan substansi hukum meniscayakan kesiapan struktur dan kultur hukum yang baru juga. Akan tetapi karena kekuatan hukum Islam lebih menitik beratkan kepada kesadaran masyarakat hukum, maka yang diutamakan adalah kesiapan dari masyarakat itu sendiri dengan cara menanamkan kesadaran bahwa melaksanakan hukum adalah bukti kepatuhan iman. Keimanan yang mendasar adalah iman kepada Allah sebagai hakim yang hakiki, yang dari-Nya lahir segala hukum dan keadilan. Oleh sebab itu, kekuatan pelaksanaan hukum pada masyarakat muslim adalah keterikatan iman mereka terhadap keharusan mentaati hukum Allah.

${ }^{12} \mathrm{Abu}$ Abdillah Muhammad bin Ismail Al Bukhary, Matnul Bukhâry Masykûl bihâsyiyah al Sindy, (Kairo: Dar el Fikr, tt), vol. III, hal.227

6|Jurnal Dakwah | Vol.1 No.1 | 2018 
Pendek kata, ayat-ayat tentang keimanan didahulukan penurunannya daripada ayat-ayat tentang hukum. Sebagaimana dikatakan Badrudin Aini, ketika ia memberi ulasan terhadap hadits tersebut:

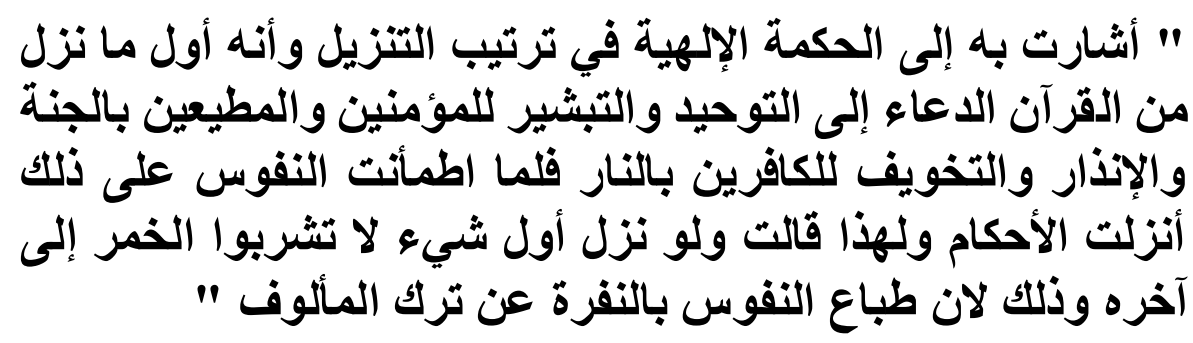

"(Kata-kata Aisyah) menunjukan kepada bikmah ilahiyah dalam tertib penurunan wabyu, dimana wabyu al Quran yang pertama turun adalah seruan kepada pengesaan Tuban, kabar gembira dengan surga bagi kaum beriman yang taat, serta ancaman neraka bagi kaum kafir. Ketika jiwa telah mantap dalam keimanan, diturunkanlah bukum-bukum. Oleb sebab itulah ia (Aisyah) mengatakan, "Sekiranya yang pertama turun adalah jangan minum khamar... dst.", bal itu dikarenakan secara psikologis suatu hal yang berat meninggalkan sesuatu yang sudah membiasa." 13

\section{KESIMPULAN}

Penjelasan dari aspek kebahasaan, maupun proses penurunan ayat Al-Qur'an dan hadits Nabi sebagaimana telah dikemukakan, dapat memberi pengertian bahwa arah tadarruj secara umum adalah dari yang mudah kepada yang susah atau dari yang ringan kepada yang berat; dari yang global kepada yang rinci; dari yang sederhana kepada yang kompleks dan sempurna. Kewajiban-kewajiban ritual, seperti shalat, puasa, dan zakat berkembang dari makna serta praktek yang sederhana ke makna dan praktek yang detil dan kompleks. Demikian juga kewajiban membela agama yang semula bersifat defensif dan menghindari konfrontasi senjata, berkembang menjadi kebolehan membela diri dengan senjata hingga diwajibkannya berjihad dengan perang.

Meski demikian, beberapa kasus menunjukan kebalikannya, yaitu berkembangnya hukum dari yang susah kepada yang mudah, dari yang berat kepada yang ringan, seperti kewajiban berperang yang semula dibebankan kepada sepuluh orang mukmin yang sabar untuk menghadapi musuh seratus orang kafir diringankan menjadi seratus orang mukmin

${ }^{13}$ Badrudin Aini al Hanafy, 'Umdah al Qâri Syarh Shahîh al Bukhâri (Beirut: Dar el Fikr, tt.), Juz XX, hlm.22. 
yang sabar menghadapi duaratus musuh yang kafir. ${ }^{14}$ Kasus yang seperti ini lazim dikatagorikan sebagai nasakh dari yang berat kepada yang ringan.

${ }^{14}$ Perhatikan Soenaryo, et. al., Al-Qur'an, Surat Al Anfal [8] ayat 65. Pembahasan nasakh yang terkait dengan tadarruj akan dibahas pada bab berikutnya

8|Jurnal Dakwah | Vol.1 No.1 |2018 